This is an electronic reprint of the original article. This reprint may differ from the original in pagination and typographic detail.

Author(s): Pesu, Laura; Aunola, Kaisa; Viljaranta, Jaana; Nurmi, Jari-Erik

Title: The Development of Adolescents' Self-concept of Ability through Grades 7-9 and the Role of Parental Beliefs

Year: $\quad 2016$

Version:

Please cite the original version:

Pesu, L., Aunola, K., Viljaranta, J., \& Nurmi, J.-E. (2016). The Development of Adolescents' Self-concept of Ability through Grades 7-9 and the Role of Parental Beliefs. Frontline Learning Research, 4(3), 92-109.

https://doi.org/10.14786/flr.v4i3.249

All material supplied via JYX is protected by copyright and other intellectual property rights, and duplication or sale of all or part of any of the repository collections is not permitted, except that material may be duplicated by you for your research use or educational purposes in electronic or print form. You must obtain permission for any other use. Electronic or print copies may not be offered, whether for sale or otherwise to anyone who is not an authorised user. 


\title{
The Development of Adolescents' Self-concept of Ability through Grades 7-9 and the Role of Parental Beliefs
}

\author{
Laura Pesu*, Kaisa Aunola, Jaana Viljaranta, \& Jari-Erik Nurmi \\ University of Jyväskylä, Finland \\ Article received 7 April / revised 4 July / accepted 8 July / available online 20 July
}

\begin{abstract}
This study examined the development of adolescents' self-concept of ability in mathematics and literacy during secondary school, and the role that mothers' and fathers' beliefs concerning their child's abilities play in this development. Also examined was whether the role of mothers' and fathers' beliefs about their adolescent child's ability in mathematics and literacy differs according to the adolescent's gender and level of performance. A total of 231 adolescents and their mothers and fathers were followed up across secondary school. The results showed, first, that adolescents' self-concept of ability declined slightly from grade 7 to grade 9 in both mathematics and literacy. Second, mothers' and fathers' beliefs about their adolescent child's abilities in grade 7 predicted the child's subsequent self-concept in grade 9, but only in mathematics. Third, the role of mothers' beliefs in their child's self-concept of mathematics ability was found to be stronger among high-performing than low-performing adolescents.
\end{abstract}

Keywords: self-concept of ability; secondary school; mother's beliefs; father's beliefs 


\section{Introduction}

Students' self-concept of ability in different academic domains, that is, the knowledge and perceptions individuals have of themselves in a particular subject area (Bong \& Skaalvik, 2003; Brunner, Keller, Hornung, Reichert, \& Martin, 2009) influences their academic performance and the academic careerrelated choices they make (Eccles et al. 1983; Marsh, Trautwein, Lüdtke, Köller, \& Baumert, 2005; Valentine, DuBois, \& Cooper, 2004; Wigfield, Eccles, Schiefele, Roeser, \& Davis-Kean, 2006). Since these self-conceptions guide students' actual performance at school and hence their future education and related decisions, it is important to identify the factors that support the development of self-concept, particularly during the critical period of adolescence when self-concept of ability typically declines (Nagy et al., 2010; Wigfield et al., 1997). Because the development of self-concept of ability has been suggested to be linked to interaction with other people (Dermitzaki \& Efklides, 2000), such as parents, the present study examined the development of self-concept of ability in literacy and mathematics among 231 Finnish adolescents from grade 7 to grade 9, and the role that mothers' and fathers' beliefs about their children's abilities play in this development. Also investigated was whether children's gender and level of performance influence the possible associations between parental beliefs and their child's self-concept of ability.

\subsection{Self-concept of ability}

Recent research has led to an understanding that self-concept is multidimensional and hierarchical in nature and is formed in social comparison and in communication with significant others (Bong \& Skaalvik, 2003). Thus, academic self-concept may be different for the domains of mathematics and verbal skills, for example (Arens, Yeung, Craven, \& Hasselhorn, 2011). Previous research has shown that mathematics and verbal self-concepts are almost uncorrelated although achievement in mathematics and verbal subjects substantially correlate (Marsh, 1990; Marsh, Byrne, \& Shavelson, 1988). The Internal/External Frame of Reference (I/E) Model focuses on explaining why this is. According to the I/E Model academic self-concept in a specific school subject is formed in relation to two comparison processes that are called "frames of reference" (Marsh \& Yeung, 2001). In the external (normative/social comparison) frame of reference a student compares his/her own performance in a particular domain (e.g. mathematics) with her/his perception of other students' performance in this domain. In the internal (ipsative-like) reference a student compares his/her own performance in a particular domain (e.g. mathematics) with his/her performance in other school subjects (e.g. literacy). The actual self-concept in a particular school domain is formed in these simultaneous comparison processes. Thus, if a student is poor in mathematics compared to other students in his/her class (external comparison), but in comparison to his/her performance in other school subjects is doing better in mathematics than in other subjects, his/her mathematics self-concept can be good. Based on the Internal/External Frame of Reference (I/E) Model, as well as previous empirical studies showing that mathematics and verbal self-concept domains are distinct (Arens et al., 2011), in the present study selfconcept is approached subject-specifically.

The Expectancy-Value theory by Eccles et al. (1983) provides a theoretical framework for selfconcept in the academic setting. According to the Expectancy-Value theory (Eccles et al., 1983; Eccles \& Wigfield, 1995; Wigfield \& Eccles, 2000) individuals' performance in school and their academic choices are explained not only by the extent to which they value the activity in question, but also by the expectancies they have for success in that activity (Wigfield \& Eccles, 2000). According to the theory, students' selfconcept of ability, that is, the individual's perception of his or her competence in a certain academic domain, influences the expectancies students have and, through these expectancies, different academic outcomes, such as performance (Wigfield \& Eccles, 2000). Theoretically, self-concept of ability is distinct from expectancy of success: self-concept of ability focuses on present ability while expectancies focus on the future. However, empirically these two concepts have not been found to be separate (Eccles et al., 1983; Wigfield \& Eccles, 2000). 
Previous research has shown that students' self-concept of ability plays an important role in academic environments by directing behavior and effort in learning situations (e.g., Atkinson, 1964; Bandura, 1986; Eccles et al., 1983; Wigfield et al., 2006). Students who believe in their abilities and expect that they can and will do well in a task are much more likely to perform better and to engage in an adaptive manner in such academic tasks than students who do not believe in their abilities and expect to fail in a certain task (Chapman, Tunmer, \& Prochnow, 2000; Eccles et al., 1983; Pintrich \& Schunk, 2008). Similar results have been found among both younger school-aged children (Chapman et al., 2000) and adolescents (Caprara, Vecchione, Alessandri, Gerbino, \& Barbaranelli, 2011; Eccles et al., 1983), and in different academic domains, such as math (Chiu \& Klassen, 2010; Eccles et al., 1983) and literacy (Chapman et al., 2000; Chiu \& Klassen, 2009). Among adolescents, self-concept of ability has further been found to predict career choices. It has been shown, for example, that students who have greater confidence in their math abilities are more likely to aspire to math-related careers than students whose confidence in their math abilities is lower (Eccles, 2007).

Several studies have shown that the development of self-concept of abilities is a continuous process that starts at the very beginning of the school career. Young students typically have very positive, and even unrealistic, perceptions of their abilities during the first years of primary school (Aunola, Leskinen, OnatsuArvilommi, \& Nurmi, 2002), but as they grow older, their perceptions of their abilities become more realistic and more negative (Jacobs, Lanza, Osgood, Eccles, \& Wigfield, 2002). One important phase for the development of self-concept of ability is early adolescence (Preckel, Niepel, Schneider, \& Brunner, 2013). During this time, many physical changes and changes in a person's environment and social context take place. At the same time an educational transition usually takes place - the transition to secondary school. This transition means changes in adolescents' everyday social contexts, in the ways adolescents get feedback in school and in their frames of reference (see Wigfield et al., 2006). The rates of self-concept of ability in mathematics and literacy have been shown to decline during elementary and secondary school (e.g. Wigfield, Eccles, MacIver, Reuman, \& Midgley, 1991). Because the earlier studies on the topic have mainly been carried out in the US (Eccles et al., 1983; Nagy et al., 2010), Australia (Nagy et al., 2010; Watt, 2004), or Germany (Nagy et al., 2010; Preckel et al., 2013), it is not known, however, whether the results on the tendency of self-concept of ability to decline during the transition to secondary school apply to other cultural and educational settings. Consequently, the first aim of the present study was to examine the developmental changes in self-concept of mathematics and literacy abilities during secondary school in Finland.

The characteristics of the Finnish school system differ from school systems in some other countries. In Finland, children start their education by attending pre-school in the year they turn 6 . In the year of their $7^{\text {th }}$ birthday children start compulsory comprehensive school which is divided into a lower level (i.e., elementary school; grades 1-6) and an upper level (i.e., secondary school; grades 7-9). In Finnish secondary schools all students are taught at the same academic level and students do not need to make decisions whether to take higher or lower level courses. This characteristic of Finnish school system is different from, for example, the system in Germany where students need to decide which achievement-based secondary school track they take (Gniewosz \& Noack, 2012). Because in Finland the compulsory courses are at the same level for everyone both high- and low-performing students are studying in the same classrooms. Moreover, in Finnish comprehensive school education extra attention is paid to support particularly those students who have difficulties in their learning. The fact that Finnish school system includes well-developed support services for students suffering, for example, from learning difficulties has been suggested to partly explain Finnish students' academic success in worldwide PISA-studies (Välijärvi et al., 2007). Overall, the fact that in Finland all students are taught at the same academic level independent of their level of performance or motivation and that extra attention is paid to support students with learning difficulties may positively impact the students' self-concept development, particularly among students showing lower performance. 


\section{$1.2 \quad$ The role of parents}

Previous studies have shown that ability-related self-concepts develop in interaction with one's environment, and are affected by evaluations of and feedback from parents (Bong \& Skaalvik, 2003; Eccles et al. 1983; Gniewosz, Eccles, \& Noack, 2014; Shavelson, Hubner, \& Stanton, 1976). According to the Expectancy-Value model proposed by Eccles and colleagues (1983), parental beliefs about their children's abilities may affect children's self-concept of ability development through at least two mechanisms (see e.g. Eccles, 1993). First, parents may directly tell their children what they think the child is good at (Jacobs \& Eccles, 2000). Second, parents can also provide different learning opportunities for their children based on their beliefs about their children's abilities (Jacobs \& Eccles, 2000). Children then interpret this information from their parents and incorporate it into their self-concept of ability (Jacobs \& Eccles, 2000).

There is also strong empirical evidence for the assumption that parents' beliefs about their children's academic performance affect children's subject-specific self-concept of ability (Eccles Parsons, Adler, \& Kaczala, 1982; Frome \& Eccles, 1998; Gniewosz, Eccles, \& Noack, 2012; Jacobs, 1991; McGrath \& Repetti, 2000; Phillips, 1987). For example, parents' beliefs in their child's success in the literacy domain have been found to be positively related to sixth-grade children's self-concept of their literacy ability (Frome \& Eccles, 1998). Similar results have been found in the domain of mathematics (Eccles Parsons et al., 1982; Gniewosz et al., 2012). Although the importance of parental beliefs in the formation of children's self-concept of mathematics and literacy ability is widely acknowledged, there is some evidence that the role of parental beliefs in the development of students' self-concept may vary with age (e.g., Gniewosz et al., 2012). For example, Pesu, Viljaranta and Aunola (2016) found that teachers' beliefs played a bigger role than parents' beliefs in first-grade students' self-concept of mathematics and literacy ability development. Gniewosz et al. (2012), in turn, found that the effects of maternal child-related competence beliefs on students' mathematics self-concept increased during the secondary school transition, whereas the effect of grades decreased. Interestingly, after the school transition the impact of maternal competence beliefs decreased and the impact of grades increased. When interpreting the previous results on the topic it should be noted that although longitudinal procedures were applied when predicting children's self-concept of ability by parental beliefs, children's self-concept of ability may also play a role in parental beliefs.

The studies focusing on the role of parental beliefs in students' self-concept of abilities have also found some gender differences. For example, it has been shown that parents typically think that boys are better at mathematics than girls (Eccles Parsons et al., 1982; Eccles \& Jacobs, 1987; Gunderson, Ramirez, Levine, \& Beilock, 2012), independently of children's actual performance in mathematics (Eccles, 1993; Eccles Parsons et al., 1982). This has been shown to impact girls' self-perceptions in mathematics (Jacobs, 1991). Conversely, parents tend to think that girls do better in literacy (Gniewosz et al., 2014). Although there are studies focusing on these mean-level-differences in parental beliefs concerning boys and girls, less is known, however, whether there is variability in the relations among parental beliefs and their children's self-concept of ability between boys and girls. According to Simpkins, Fredricks, and Eccles (2012) it is important to study whether the associations among the indicators vary as a function of gender because socialization and cognitive theories suggest that the associations are not similar for boys and girls. According to these theories adolescents most likely act in a similar way as people who are most similar to themselves (Maccoby, 1998). This suggests that mothers may have a stronger impact on their daughters than to their sons and fathers on their sons than their daughters (Maccoby, 1998). Furthermore, testing the moderating effect of gender is important because it may have important implications for interventions (Simpkins et al., 2012): if parental beliefs have different impact on boys and girls self-concept of ability, the interventions should take this into consideration when thinking the best ways to support girls and boys. Whether the effect of parental beliefs about their children's abilities on children's self-concept development is affected by the child's gender is thus far, however, underexplored.

Alongside gender it has been recently suggested that the child's level of performance may also impact the association between adults' beliefs and students' self-concept of ability (Pesu et al., 2016). In the study by Pesu et al. (2016), the impact of teachers' beliefs on first-grade students' self-concept of 


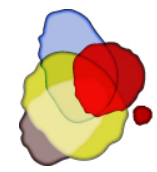

mathematics and reading ability was different depending on the level of student's performance: among highperforming students, teachers' beliefs had a positive impact on students' self-concept of mathematics and reading ability, whereas among low-performing students, teachers' beliefs did not have this positive impact. Pesu et al. (2016) suggested that one explanation for this differential impact of teacher beliefs is that highperforming children are more prone to be affected by adults' beliefs than low-performing children as (owing to their cognitive abilities) they are able to make more accurate interpretations of adults' feedback and their own performance. Also, Bohlmann and Weinstein (2013) argued that children's cognitive reasoning skills affect the way they perceive, interpret, and attribute meaning to teachers' actions. Thus, it can be that students who have better cognitive skills are better able to interpret adults' feedback overall. However, the differential role that parental beliefs have on student self-concept, depending on the student's level of performance, has not to our knowledge been investigated among older children like secondary school students. Finding out differences in the associations between parental beliefs and students' self-concept of ability depending on students' level of performance might have important implications for interventions.

One further limitation of earlier research is that the majority of studies on the role of parental beliefs have focused on the role of mothers (for exceptions, see Frome \& Eccles, 1998; Gniewosz \& Noack, 2012; Pesu et al., 2016), to the relative neglect of the role of fathers' beliefs. However, it might be that mothers and fathers play a different role in their children's self-concept development (Frome \& Eccles, 1998; MacGrath $\&$ Repetti, 2000; Maccoby, 1998). Consequently, the second aim of the present study was to investigate the role of mothers' and fathers' beliefs about their adolescent children's abilities in mathematics and literacy in the development of adolescents' self-concept of ability during secondary school. Further, possible differences in these associations depending on the adolescent's gender, on the one hand, and level of performance, on the other, were investigated.

The research questions were:

a) To what extent Finnish adolescents' self-concept of mathematics and literacy ability change during secondary school? Based on earlier literature, we hypothesized that self-concept of mathematics and literacy ability decline during grades 7-9 (Nagy et al., 2010; Wigfield et al., 1991).

b) Do parental beliefs concerning adolescents' abilities predict the development of adolescents' self-concept of literacy and mathematics ability during grades 7-9? We hypothesized that mothers' and fathers' beliefs positively predict adolescents' subsequent self-concept of literacy and mathematics ability (e.g. Frome \& Eccles, 1998; Gniewosz et al., 2012).

c) Are there differences in the associations between parental beliefs and adolescents' selfconcept of abilities depending on adolescents' a) gender, b) level of performance? We set two alternative hypotheses concerning the gender differences in the associations. As the first hypothesis, we hypothesized that the associations of mothers' beliefs with adolescents' selfconcept of ability are stronger among girls than among boys whereas the associations of fathers' beliefs with adolescents' self-concept of ability are stronger among boys than among girls, as suggested by the socialization model (Maccoby, 1998). As the second hypothesis, we hypothesized that gender does not play a role in the connections between mothers'/fathers' beliefs and self-concept of ability because previous studies have not found these kinds of gender differences (Pesu at al., 2016; Simpkins et al., 2012). Based one previous results by Pesu et al. (2016), we also hypothesized that the role of mothers'/fathers' beliefs in self-concept of ability is stronger among high- than low-performing students. 


\section{Method}

\subsection{Participants}

The present study is a part of a longitudinal study (the Jyväskylä Entrance into Primary School (JEPS) study (Nurmi \& Aunola, 1999-2009)) focusing on students' academic and motivational development from the beginning of the school career until the end of comprehensive school. The sample comprised students from two medium-sized districts (urban or semi-urban areas) in central Finland. The present study focuses on the data obtained from the adolescents and their parents when the former were in the $7^{\text {th }}$ and $9^{\text {th }}$ grades. The participants were 231 students in grade 7 and 221 in grade 9 (in grade 7: 114 girls and 117 boys, in grade 9:107 girls and 114 boys $)$ and their mothers $(n=221)$ and fathers $(n=191)$. The adolescents filled in questionnaires on their self-concept of ability in the spring of the $7^{\text {th }}$ grade and again in the spring of the $9^{\text {th }}$ grade. Performance in mathematics and literacy was assessed by tests in the spring term of the $7^{\text {th }}$ grade. All questionnaires and tests were performed during regular school hours in classroom group situations by trained investigators. Mothers and fathers were asked to fill in mailed questionnaires concerning their beliefs about their child's performance in mathematics and literacy in the spring of the grade 7 . The response rate was $96 \%$ for mothers and $83 \%$ for fathers.

The families participating in the study were to some extent more educated than the Finnish population overall (Statistics Finland, 2010): 11.5\% of mothers and 12.1\% of fathers had no vocational education, $26.6 \%$ of mothers and $38.4 \%$ of fathers had a vocational education, and $61.9 \%$ of mothers and $49.6 \%$ of fathers had a degree from an institution of higher learning (e.g., polytechnic) or university. At the beginning of the $7^{\text {th }}$ grade, $68,3 \%$ of the children were living in a nuclear family, $13,5 \%$ were living in a blended family, and $9,1 \%$ were living in a single parent household.

\subsection{Measures}

\subsubsection{Self-concept of ability in literacy and mathematics}

Students' self-concept of ability in mathematics and literacy was measured with a questionnaire based on the ideas presented by Eccles and Wigfield (1995). Students were asked to answer three questions, separately for mathematics and literacy (How good are you at mathematics / literacy? How good do you think you are at mathematics / literacy compared to the other students in your class? How hard are assignments related to mathematics / literacy for you (revised)) on a 5-point Likert-scale. Self-concept of ability in mathematics and literacy were scored separately by calculating the mean of the three items in each case. The Cronbach's alpha reliabilities for self-concept in mathematics in grade 7 and grade 9 were .87 and .89 , respectively, and for self-concept in literacy .81 and .81 , respectively.

\subsubsection{Adolescents' performance in mathematics}

Adolescents' performance in mathematics was assessed with the group-administered KTLT test (Räsänen \& Leino, 2005), which is a standardized math test for grades 7-9 (13-16 years). The test consists of 40 mathematical tasks (basic calculation and equation tasks, word problems, geometry tasks, measurement tasks), to be done individually. One point was given for each correct answer. The test was administered with a 45 -minute time limit. The internal reliability of the test in the present data was .86. The internal reliability of the test in the normative data $(\mathrm{N}=1,157)$ has been shown to be 0.88 (Räsänen \& Leino, 2005). The test has also been shown to correlate with other measures of mathematical skills $(r=0.61-0.78, p<0.001$; Räsänen \& Leino, 2005). 


\subsubsection{Adolescents' performance in literacy}

Adolescents' performance in literacy was measured by three subtests taken from the Test of Word Reading, Spelling and Reading Comprehension (Holopainen, Kairaluoma, Nevala, Ahonen, \& Aro, 2004):

a) In the first spelling error task, participants were asked to mark with a vertical line on 100 words typed on a sheet of paper as many spelling errors (an extra, missing, or wrong letter in a word) as they could identify in 3.5 minutes. The score was the number of correctly detected errors. The test-retest reliability for the subtest has been shown to be 0.83 (Holopainen et al., 2004).

b) In the second word chain test, the participants were asked to separate understandable words in a word chain by drawing a line between the words. A total of 100 words were presented in chains of four words with no spaces between them. The adolescents were allowed 3.5 minutes to find the end of one word and the beginning of a new word in each chain and to mark it with a vertical line. The test was scored as the number of correctly found words. The test-retest reliability of the subtest has been shown to be 0.84 (Holopainen et al., 2004).

c) In the reading comprehension test, the participants were asked to read a four-page long story (The Hounds of the Village, written by Finnish author Veikko Huovinen), in which 52 words had been changed so that they did not fit in with the story (i.e., they were in contradiction with the meaning of the sentence, paragraph or larger text context). The participants were asked to underline all the inappropriate words they could find. A point was given for each correctly underlined word. The time limit for the subtest was 45 minutes.

The sum score of the standardized three subtest scores was taken as the measure of literacy performance. The Cronbach's alpha reliability of the sum score was .81.

\subsubsection{Mothers' and fathers' beliefs about their child's performance in literacy/mathematics}

Mothers' and fathers' beliefs were measured at the end of the $7^{\text {th }}$ grade with 2 items (e.g. How well do you think your child is doing in literacy/mathematics at the moment? How well do you think your child will do in literacy/mathematics in the future?) using a 4-point Likert-scale. The Cronbach alpha reliabilities of the scale were .92 (literacy) and .93 (mathematics) among mothers and .92 (literacy) and .93 (mathematics) among fathers.

\subsubsection{Analyses strategy}

The analyses were carried out along the following steps. First, the developmental changes in adolescents' self-concepts of mathematics and literacy abilities from grade 7 to grade 9 , and possible gender differences in these changes, was investigated by repeated measures ANOVA. Second, hierarchical regression analyses were carried out to examine whether parents' beliefs about their adolescent children's abilities in mathematics and literacy play a role in the development of adolescents' self-concept of mathematics and literacy ability during secondary school and whether the role of parental beliefs differs according to the adolescent's gender or level of performance. In these analyses, adolescents' self-concept of ability in a specific school subject in the spring of the ninth grade (Time 2) was predicted by their selfconcept of ability in that subject in the spring of the seventh grade (Time 1), academic performance in that subject in the seventh grade (Time 1), gender, and mothers' or fathers' beliefs about their child's abilities in the spring of the seventh grade (Time 1). Each variable was entered stepwise in the analysis. The effects of mothers' and fathers' beliefs were tested in separate analyses. In order to determine whether any connection existed between mothers'/fathers' beliefs and the adolescents' subsequent level of self-concept of ability was influenced by the adolescents' gender or by the adolescents' level of performance, the related interaction terms (Gender X Belief or Academic Performance X Belief) were added to the analysis in the last step. Each interaction term was tested in a separate analysis. The analysis was carried out separately for self-concept of mathematics ability and self-concept of literacy ability. In order to be able to examine the effects of the 
interaction terms, all the predictor variables were standardized before being added to the regression models and before calculating any interaction terms. The missing data was handled pairwise.

\section{Results}

The means $(M)$, standard deviations $(S D)$, and Pearson product-moment-correlations of the study variables are shown in Table 1.

The results of repeated measures ANOVA showed that adolescents' self-concept of mathematics ability slightly declined from grade $7(M=3.41, S D=0.82)$ to grade $9(M=3.30, S D=0.94 ; F(1,202)=$ $5.87, p<.05$ ). Their self-concept of literacy also slightly declined during this period (Time $1: M=3.54, S D$ $=0.70$; Time $2: M=3.44, S D=0.72 ; F(1,203)=3.86, p=.05)$. Self-concept of literacy ability was higher among girls than boys across the measurement points $(F(1,202)=21.14, p<.001)$, whereas self-concept of math ability was higher among boys than girls $(F(1,202)=6.23, p<.05)$. No gender differences in the change in self-concepts from grade 7 to grade 9 were, however, evident. 
Table 1

Intercorrelations, Means, and Standard Deviations for the study variables

\begin{tabular}{|c|c|c|c|c|c|c|c|c|c|c|c|c|}
\hline & Variables & 1. & 2. & 3. & 4. & 5. & 6. & 7. & 8. & 9. & 10 & 11 \\
\hline 1. & Self-concept Literacy T1 & & & & & & & & & & & \\
\hline 2. & Self-concept Literacy T2 & $.48^{\mathrm{c}}$ & & & & & & & & & & \\
\hline 3. & Self-concept Math T1 & .12 & $.20^{\mathrm{b}}$ & & & & & & & & & \\
\hline 4. & Self-concept Math T2 & .08 & $.29^{\mathrm{c}}$ & $.71^{\mathrm{c}}$ & & & & & & & & \\
\hline 5. & Performance Literacy T1 & $.38^{\mathrm{c}}$ & $.45^{\mathrm{c}}$ & $.23^{\mathrm{b}}$ & $.23^{\mathrm{b}}$ & & & & & & & \\
\hline 6. & Performance Math T1 & $.26^{\mathrm{c}}$ & $.27^{\mathrm{c}}$ & $.59^{\mathrm{c}}$ & $.51^{\mathrm{c}}$ & $.60^{\mathrm{c}}$ & & & & & & \\
\hline 7. & Gender & $-.21^{\mathrm{b}}$ & $-.32^{\mathrm{c}}$ & $.17^{\mathrm{b}}$ & $.14^{\mathrm{a}}$ & $-.36^{\mathrm{c}}$ & .00 & & & & & \\
\hline 8. & Mother belief Literacy $\mathrm{T} 1$ & $.46^{\mathrm{c}}$ & $.40^{\mathrm{c}}$ & $.29^{\mathrm{c}}$ & $.23^{\mathrm{b}}$ & $.57^{\mathrm{c}}$ & $.46^{\mathrm{c}}$ & $-.30^{\mathrm{c}}$ & & & & \\
\hline 9. & Mother belief Math T1 & .09 & $.16^{\mathrm{a}}$ & $.64^{\mathrm{c}}$ & $.62^{\mathrm{c}}$ & $.39^{\mathrm{c}}$ & $.64^{\mathrm{c}}$ & -.01 & $.53^{\mathrm{c}}$ & & & \\
\hline 10. & Father belief Literacy T1 & $.35^{\mathrm{c}}$ & $.35^{\mathrm{c}}$ & $.25^{\mathrm{b}}$ & $.24^{\mathrm{b}}$ & $.51^{\mathrm{c}}$ & $.48^{\mathrm{c}}$ & $-.28^{\mathrm{c}}$ & $.56^{\mathrm{c}}$ & $.38^{\mathrm{c}}$ & & \\
\hline 11. & Father belief Math T1 & .01 & .06 & $.54^{\mathrm{c}}$ & $.55^{\mathrm{c}}$ & $.32^{\mathrm{c}}$ & $.56^{\mathrm{c}}$ & .02 & $.40^{\mathrm{c}}$ & $.67^{\mathrm{c}}$ & $.58^{\mathrm{c}}$ & \\
\hline$M$ & & 3.56 & 3.47 & 3.36 & 3.30 & 46.34 & 21.52 & & 2.90 & 2.76 & 2.87 & 2.84 \\
\hline$S D$ & & .69 & .74 & .84 & .94 & 14.43 & 6.33 & & .79 & .80 & .69 & .76 \\
\hline
\end{tabular}

Note. ${ }^{\mathrm{a}}=p<.05 .{ }^{\mathrm{b}}=p<.01 .^{\mathrm{c}}=p<.001$.

$\mathrm{T} 1=$ time $1, \mathrm{~T} 2=$ time 2 


\subsection{Math-related self-concept}

The results of the hierarchical regression analyses for mathematics-related self-concept (see Table 2) showed, first, that individual differences in self-concept of mathematics ability were relatively stable from grade 7 to grade 9 . Second, mothers' $(\beta=.28, p<.001)$ and fathers' $(\beta=.22, p<.001)$ beliefs about their child's abilities predicted adolescents' subsequent self-concept of mathematics ability at the end of grade 9 , after controlling for the previous levels of self-concept of mathematics ability and mathematics performance: the higher the beliefs parents had about their child's mathematics ability in grade 7, the better the adolescents' self-concept of mathematics ability was in grade 9. Finally, the connections between adolescents' self-concept of mathematics ability and mothers' belief in mathematics was found to be different depending on the adolescent's level of mathematics performance $(\beta=.13, p<.01)$. To examine this interaction effect further, Aiken and West's (1991) procedure was used. In this procedure, simple slopes for the mothers' belief variable in the prediction of adolescents' mathematics self-concept were calculated and presented using standardized scores separately for adolescents who showed either low $(-1 S D)$ or high $(+1$ $S D$ ) levels of mathematics performance. The results are shown in Figure 1. The results showed that among high-performing adolescents, mothers' beliefs positively predicted subsequent self-concept of mathematics ability, whereas among low-performing adolescents this positive effect of mothers' beliefs was weaker. The impact of parental beliefs was similar for boys and girls.

Table 2

The Results of Hierarchical Regression Analyses for Mathematics Related Self-Concept at Time 2 (Standardized Betas)

\begin{tabular}{|c|c|c|c|c|c|}
\hline \multirow[b]{2}{*}{ Predictor } & \multicolumn{3}{|c|}{$\begin{array}{c}\text { Mathematics Related Self-Concept } \\
\text { at Time } 2\end{array}$} & \multirow[b]{2}{*}{$\begin{array}{l}\text { Step4 } \\
\beta\end{array}$} & \multirow[b]{2}{*}{$\begin{array}{l}\text { Step5 } \\
\beta\end{array}$} \\
\hline & $\begin{array}{l}\text { Step 1 } \\
\beta\end{array}$ & $\begin{array}{l}\text { Step2 } \\
\beta\end{array}$ & $\begin{array}{l}\text { Step3 } \\
\beta\end{array}$ & & \\
\hline A. Self-concept (Time 1) & $.71^{* * *}$ & $.71 * * *$ & $.62 * * *$ & $.50 * * *$ & $.47 * * *$ \\
\hline B. Gender & & .02 & .04 & .06 & .07 \\
\hline C. Performance (Time 1) & & & $.14^{*}$ & .03 & .06 \\
\hline \multicolumn{6}{|l|}{ D. Beliefs } \\
\hline D1. Beliefs mother (Time 1) & & & & $.28 * * *$ & $.30 * * *$ \\
\hline D2. Beliefs father (Time 1) & & & & $.22 * *$ & $.23 * *$ \\
\hline \multicolumn{6}{|l|}{ E. Interaction Terms } \\
\hline B X D1 & & & & & -.16 \\
\hline B X D2 & & & & & .05 \\
\hline C X D1 & & & & & $.13 * *$ \\
\hline C X D2 & & & & & .04 \\
\hline & $R^{2}=.51$ & $R^{2}=.51$ & $R^{2}=.52$ & $R^{2}=.55-.56^{1}$ & $R^{2}=.55-.57^{1}$ \\
\hline
\end{tabular}

Note $1 . * * * p<.001, * * p<.01, * p<.05$

The effects of mothers' and fathers' beliefs were each tested in separate analyses. Similarly all interaction terms were tested in separate analyses.

${ }^{1} R^{2}$ varies depending on which variables are included into the model as predictor variables. 
Figure 1. The impact of mothers' beliefs on students' mathematics related self-concept among low, medium and high-performing students

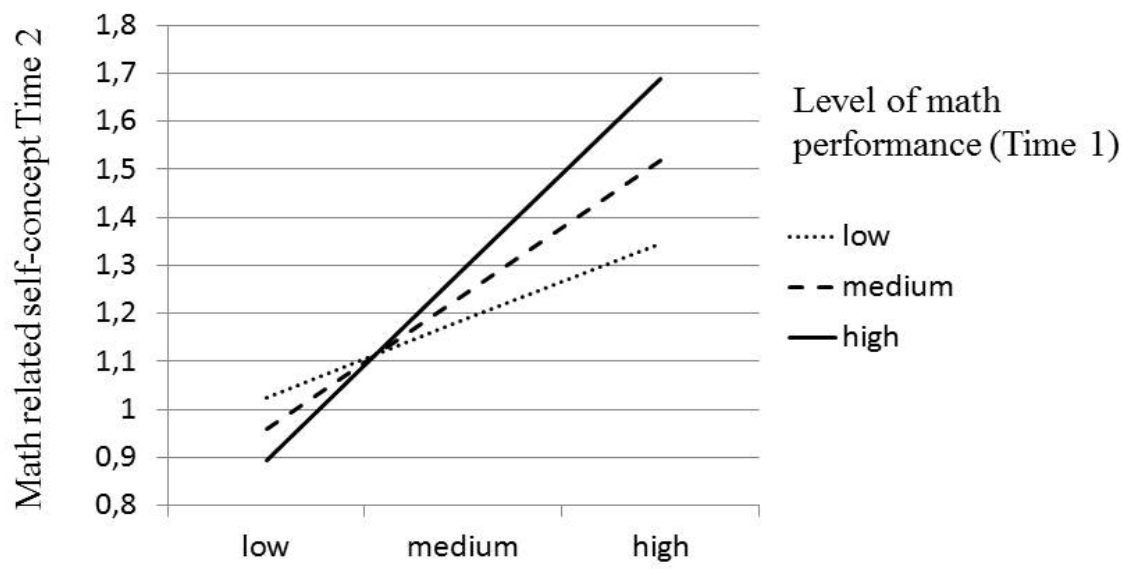

Level of mother belief (Time 1)

\subsection{Literacy-related self-concept}

The results of hierarchical regression analyses (see Table 3) showed, first, that individual differences in self-concept of literacy ability were relatively stable through grades 7-9. The results showed further that, after controlling for the previous level of self-concept and literacy performance, mothers' or fathers' beliefs did not predict adolescents' self-concept of literacy ability. No Parental Belief X Gender or Parental Belief X Performance interaction effects were found either. 
Table 3

The Results of Hierarchical Regression Analyses for Literacy Related Self-Concept at Time 2 (Standardized Betas)

\begin{tabular}{|c|c|c|c|c|c|}
\hline \multirow[b]{2}{*}{ Predictor } & \multicolumn{3}{|c|}{$\begin{array}{c}\text { Literacy Related Self-Concept } \\
\text { at Time } 2\end{array}$} & \multirow[b]{2}{*}{$\begin{array}{l}\text { Step4 } \\
\beta\end{array}$} & \multirow[b]{2}{*}{$\begin{array}{l}\text { Step5 } \\
\beta\end{array}$} \\
\hline & $\begin{array}{l}\text { Step } 1 \\
\beta\end{array}$ & $\begin{array}{l}\text { Step2 } \\
\beta\end{array}$ & $\begin{array}{l}\text { Step } 3 \\
\beta\end{array}$ & & \\
\hline A. Self-concept (Time 1) & $.48^{* * *}$ & $.43 * * *$ & $.34 * * *$ & $.32 * * *$ & $.32 * * *$ \\
\hline B. Gender & & $-.23 * * *$ & $-.15^{*}$ & $-.15^{*}$ & $-.15^{*}$ \\
\hline C. Performance (Time 1) & & & $.27 * * *$ & $.24 * *$ & $.24 * *$ \\
\hline \multicolumn{6}{|l|}{ D. Beliefs } \\
\hline D1. Beliefs mother (Time 1) & & & & .08 & .08 \\
\hline D2. Beliefs father (Time 1) & & & & .08 & .09 \\
\hline \multicolumn{6}{|l|}{ E. Interaction Terms } \\
\hline B X D1 & & & & & .21 \\
\hline B X D2 & & & & & .03 \\
\hline C X D1 & & & & & .02 \\
\hline C X D2 & & & & & .08 \\
\hline & $R^{2}=.23$ & $R^{2}=.28$ & $R^{2}=.33$ & $R^{2}=.34$. & $R^{2}=.34$ \\
\hline
\end{tabular}

Note $1 .{ }^{* * *} p<.001,{ }^{* *} p<.01,{ }^{*} p<.05$

The effects of mothers' and fathers' beliefs were each tested in separate analyses. Similarly all interaction terms were tested in separate analyses.

\section{Discussion}

The present study aimed to contribute to the literature on students' self-concept of ability by examining, first, to what extent developmental changes in self-concept of mathematics and literacy abilities occur among Finnish students across secondary school and, second, what role mothers' and fathers' beliefs play in the development of adolescents' self-concept of mathematics and literacy ability during this period. Furthermore, whether the possible associations of parental beliefs with adolescents' self-concepts of abilities are influenced by adolescents' gender or level of performance was investigated. The results showed first that both self-concept of mathematics and literacy ability slightly declined during secondary school. Second, mothers' and fathers' beliefs about their child's abilities predicted changes in the adolescents' self-concept of ability, but only in mathematics: the higher the beliefs parents had about their child's mathematics ability in grade 7, the better the adolescents' subsequent self-concept of mathematics ability was in grade 9. Furthermore, the role of mothers' beliefs in adolescents' self-concept of mathematics ability was found to be particularly strong among those adolescents who showed a high level of mathematics performance. Finally, gender did not have an effect on the connections between parental beliefs and adolescents' self-concept of ability development in mathematics or literacy.

\subsection{The Development of Self-Concept of Ability}

The results of this study showed first that adolescents' self-concept slightly declined during secondary school among both girls and boys. This result is consistent with previous results reported among US (Nagy et al., 2010; Wigfield et al., 1991), German (Nagy et al., 2010) and Australian students (Nagy et 
al., 2010) and suggest that also in the Finnish context the secondary school years are an important time for the development of self-concept. The period of the transition to secondary school brings many changes in adolescents' lives. Their everyday social contexts change, the ways they get feedback at school change, and their frames of reference change (see Wigfield et al., 2006). It is noteworthy, however, that in the present study the decline in self-concept was only minor. One explanation for there being only a slight decline in self-concept can be found in the Finnish national curriculum guidelines, according to which teachers should focus on motivating both boys and girls equally to learn and to help them build a positive self-concept. Thus, it is possible that since Finnish teachers are aware of the importance of supporting self-concept construction, students receive much support from their school in this area, and thus show less of a decline in self-concept during adolescence.

\subsection{The Role of Mothers' and Fathers' Beliefs in Self-Concept of Ability Development}

The results of the present study showed further that mothers' and fathers' beliefs predicted students' self-concept of mathematics ability development across secondary school: the higher parental beliefs at the beginning of secondary school, the higher the adolescent's self-concept in mathematics at the end of secondary school. The results are in line with Eccles et al.'s Expectancy-Value theory which suggests that parental beliefs affect their children's self-concept of ability (Eccles Parsons et al., 1982; Frome \& Eccles, 1998; Lau \& Pun, 1999; McGrath \& Repetti, 2000). Previous empirical research on the role of parents in students' self-concept of ability development, however, has mainly focused on the role of mothers' beliefs whereas that of fathers' has received less attention. However, there is some evidence that mothers and fathers both play a role in their children's self-concept of ability development in both mathematics and literacy (Frome \& Eccles, 1998; Gniewosz et al., 2014) at least among sixth-grade students (Frome \& Eccles, 1998) and fifth- to seventh-graders (Gniewosz et al., 2014). The results of the present study also indicate that in secondary school both mothers' and fathers' beliefs have an impact on adolescents' self-concept of ability in the domain of mathematics. This result adds to the literature since previous studies on the role of parents have not focused on this particular age group.

However, the present results are inconsistent with those of previous research insofar as mothers' and fathers' beliefs did not play a role in their adolescents' self-concept development in the domain of literacy. There are several possible explanations for this result. First, it is possible that achievement feedback is less clear in literacy than in mathematics, which would help explain why parents had a more evident role in adolescents' self-concept development in mathematics. Another possibility is that because mathematics is typically considered a more difficult school subject than literacy, and because there is a clearer declining trend in the self-concept of mathematics ability, the self-concept of mathematics ability is particularly prone to external feedback. Third, previous studies showing connections between parental beliefs and their children's self-concept of ability development have been conducted in cultural settings other than Finland. Research has revealed that Finnish children attain fluency in native language reading and writing earlier, by the end of the first school year (Seymour, Aro, \& Erskine, 2003) than for example English-speaking children, whose rate of literacy skills development is more than twice as slow (Seymour et al., 2003). Slower literacy skills development has been attributed to fundamental linguistic differences in syllabic complexity and orthographic depth (Seymour et al., 2003). For this reason, Finnish parents might involve themselves less in their children's literacy-related studies than mathematics studies, also later on. Thus, parents might have less information about their children's success in literacy than in mathematics and thus less influence on their children's self-concept in literacy than in mathematics.

The results of the present study showed, finally, that the role of mothers' beliefs about their adolescent child's mathematics ability was dependent on the level of the adolescent's performance: mothers beliefs were positively related to their children's self-concept of mathematics ability among high-performing adolescents but less so among low-performing adolescents. These results are in line with the results of Pesu et al. (2016), who found that the role of teachers' beliefs on first graders' self-concept of mathematics and reading ability differed depending on the level of the student's performance: teachers' beliefs had a positive 


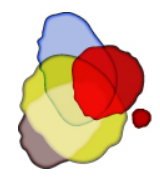

impact on students' self-concept of mathematics and reading ability only among high-performing students, not among low-performing students. There are several possible explanations for this result that mothers' beliefs play a role, particularly among high-performing children. First, it might be that mothers communicate their beliefs, even where they are equally positive, differently to children whose levels of performance are different. Thus, the effect of mothers' beliefs would be different for children who perform differently at school. Second, it could be that students interpret mothers' cues about their beliefs differently depending on their level of performance. Bohlmann and Weinstein (2013) argued that children's cognitive abilities influence their perceptions and interpretations of teachers' actions. It is possible that children's cognitive abilities influence their perceptions of external feedback overall. Thus, it could be that high-performing adolescents are cognitively better able to accurately perceive and interpret mothers' beliefs (see also, Pesu et al., 2016).

The present study showed that gender had no effect on the development of self-concept of ability in either mathematics or literacy. This result is consistent with previous studies showing similar patterns in the development of self-concept in boys and girls (e.g. Nagy et al., 2010). The results of the present study showed further that gender did not influence the relationship between mothers' and fathers' beliefs and adolescents' self-concept of ability development. Since Finland can be considered an egalitarian culture (Chiu \& Klassen, 2009; Chiu \& Klassen, 2010), there might be fewer gender differences overall. In an egalitarian culture, individuals are taught to view, value, and act towards one another as equals based on their common humanity (Chiu \& Klassen, 2009; Chiu \& Klassen, 2010). People learn these practices and values through formal and informal socialization, including through schooling (Chiu \& Klassen, 2009; Chiu \& Klassen, 2010). Finnish culture is also considered as having little characteristics of a masculine culture (Chiu \& Klassen, 2009; Chiu \& Klassen, 2010). In masculine cultures males are typically favored in higher status roles, and women have lower income (Cheung \& Chan, 2007). Because gender roles are rigid in masculine cultures, this may lead, for example, girls to value mathematics learning less, devote less time to studying mathematics and have lower mathematics self-concept than boys (Hofstede, 2003; Wigfield, Tonks, \& Eccles, 2004). As Finland is considered an egalitarian and less masculine culture than many other cultures (Chiu \& Klassen, 2009; Chiu \& Klassen, 2010), Finnish children grow up in a society where boys and girls are treated more equally than in cultures that are less egalitarian. This may explain why the present study did not show any gender differences in girls' and boys' self-concept of abilities and why the impact of parental beliefs was similar for boys and girls.

\subsection{Limitations}

This study has its limitations. First, the study was carried out in just one educational setting, Finland. As it is possible that parental beliefs play a different role in students' self-concept of abilities in different educational settings and cultures, further cross-cultural research on the topic is needed. Second, even though a longitudinal procedure was used in the present study, it might be that some third factor not controlled for explains the predictions found. One should, therefore, be cautious before making any judgements about the possible causality of the results. Third, the measure for mothers' and fathers' beliefs included two questions only. In future research measurements including more items to measure parental beliefs should be used to replicate the results found here.

Overall, the results of this study suggest that during secondary school Finnish adolescents' selfconcepts of mathematics and literacy ability undergo a slight decline, and that in the domain of mathematics both mothers' and fathers' beliefs about their children's abilities play a role in the development of adolescents' self-concept of ability. It is important that both mothers and fathers know what role they play in the formation of their children's self-concepts of ability. Because parents receive information about their children's success at school indirectly, i.e. via grades and feedback from teachers, they might tend to think they do not have much of a role in their children's academic-related life. It is important that schools and teachers in particular inform parents about the crucial role they can have on their children's self-concept development in different academic domains. Teachers and school personnel should inform parents about the 
ways in which they, both mothers and fathers, could support their children and their children's developing self-concepts.

\section{Keypoints}

- Mothers' and fathers' child-specific ability beliefs predicted adolescents' self-concept of mathematics ability.

- Mothers' and fathers' beliefs did not predict adolescents' self-concept of literacy ability.

- The relations between mothers' beliefs and adolescents' self-concept of mathematics ability varied according to adolescents' performance: mothers beliefs were positively related to their children's self-concept of mathematics ability among high-performing adolescents but less so among low-performing adolescents.

\section{References}

Aiken, L. S., \& West, S. G. (1991). Multiple Regression: Testing and interpreting interactions. Newbury Park, CA: Sage.

Arens, A. K., Yeung, A. S., Craven, R. G., \& Hasselhorn, M. (2011). The twofold multidimensionality of academic self-concept: Domain specificity and separation between competence and affect components. Journal of Educational Psychology, 103, 970-981. doi: 10.1037/a0025047

Atkinson, J. W. (1964). An introduction to motivation. Princeton, NJ: Van Nostrand.

Aunola, K., Leskinen, E., Onatsu-Arvilommi, T., \& Nurmi, J-E. (2002). Three methods for studying developmental change: A case of reading skills and self-concept. British Journal of Educational Psychology, 72, 343-364. doi: 10.1348/000709902320634447

Bandura, A. (1986). Social foundations of thought and action: A social cognitive theory. Englewood Cliffs, NJ: Prentice-Hall.

Bohlmann, N., \& Weinstein, R. (2013). Classroom context, teacher expectations, and cognitive level: Predicting children's math ability judgments. Journal of Applied Developmental Psychology, 34, 288298. doi: 10.1016/j.appdev.2013.06.003

Bong, M., \& Skaalvik, E. M. (2003). Academic self-concept and self-efficacy: How different are they really? Educational Psychology Review, 15, 1-40. doi: 10.1023/A:1021302408382

Brunner, M., Keller, U., Hornung, C., Reichert, M., \& Martin, R. (2009). The cross-cultural generalizability of a new structural model of academic self-concepts. Learning and Individual Differences, 19, 387-403. doi:10.1016/j.lindif.2008.11.008

Caprara, G. V., Vecchione, M., Alessandri, G., Gerbino, M., \& Barbaranelli, C. (2011). The contribution of personality traits and self-efficacy beliefs to academic achievement: A longitudinal study. British Journal of Educational Psychology, 81, 78-96. doi: 10.1348/2044-8279.002004

Chapman, J. W., Tunmer, E. T., \& Prochnow, J. E. (2000). Early reading-related skills and performance, reading self-concept, and the development of academic self-concept: A longitudinal study. Journal of Educational Psychology, 92, 703-708. doi: 10.1037/0022-0663.92.4.703

Cheung, H. Y., \& Chan, A. W. H. (2007). How culture affects female inequality across countries. Journal of Studies in International Education, 11, 157-179. doi: 10.1177/1028315306291538

Chiu, M. M., \& Klassen, R. M. (2009). Calibration of reading self-concept and reading achievement among 15-year-olds: Cultural differences in 34 countries. Learning and Individual Differences, 19, 372-386. doi:10.1016/j.lindif.2008.10.004

Chiu, M. M., \& Klassen, R. M. (2010). Relations of mathematics self-concept and its calibration with mathematics achievement: Cultural differences among fifteen-year-olds in 34 countries. Learning and Instruction, 20, 2-17. doi:10.1016/j.learninstruc.2008.11.002 
Dermitzaki, I., \& Efklides, A. (2000). Aspects of self-concept and their relationship to language performance and verbal reasoning ability. The American Journal of Psychology, 113, 621-637. doi: $10.2307 / 1423475$

Eccles, J. S. (1993). School and family effects on the ontogeny of children's interests, self-perceptions, and activity choices. In J. E. Jacobs \& R. Dienstbier (Eds.), Developmental perspectives on motivation (pp. 145-208). University of Nebraska Press.

Eccles, J. S. (2007). Where are all the women? Gender differences in participation in physical science and engineering. In S. J. Ceci \& W. M. Williams (Eds.), Why aren't more women in science? Top researchers debate the evidence (pp. 199-210). Washington, DC: American Psychological Association. doi:10.1037/11546-016

Eccles, J. S., Adler, T. F., Futterman, R., Goff, S. B., Kaczala, C. M., Meece, J. L., \& Midgley, C. (1983). Expectancies, values, and academic behaviors. In J. T. Spence (Ed.), Achievement and achievement motivation (pp. 75-146). San Francisco: W. H. Freeman.

Eccles Parsons, J., Adler, T. F., \& Kaczala, C. M. (1982). Socialization of achievement attitudes and beliefs: Parental influences. Child Development, 53, 310-321. doi: 10.2307/1128973

Eccles, J. S., \& Jacobs, J. E. (1987). Social forces shape math attitudes and performance. In M. R. Walsh (Ed.), The psychology of women: Ongoing debates (pp. 341-354). New Haven, US: Yale University Press.

Eccles, J. S., \& Wigfield, A. (1995). In the mind of the actor: The structure of adolescents' achievement task values and expectancy-related beliefs. Personality and Social Psychology Bulletin, 3, 215-225. doi: $10.1177 / 0146167295213003$

Frome, P. M., \& Eccles, J. S. (1998). Parents' influence on children's achievement-related perceptions. Journal of Personality and Social Psychology, 74, 435-452. doi: 10.1037/0022-3514.74.2.435

Gniewosz, B., Eccles, J. S., \& Noack, P. (2012). Secondary school transition and the use of different sources of information for the construction of the academic self-concept. Social Development, 21, 537-557. doi: 10.1111/j.1467-9507.2011.00635.x

Gniewosz, B., Eccles, J. S., \& Noack, P. (2014). Early adolescents' development of academic self-concept and intrinsic task value: The role of contextual feedback. Journal of Research on Adolescence, 25, 1-15. doi: 10.1111 jora.12140.

Gniewosz, B., \& Noack, P. (2012). Mamakind or Papakind? [Mom's Child or Dad's Child]: Early adolescents' parental preferences in intergenerational academic value transmission. Learning and Individual Differences, 22, 544-548. doi:10.1016/j.lindif.2012.03.003

Gunderson, E. A., Ramirez, G., Levine, S. C., \& Beilock, S. I. (2012). The role of parents and teachers in the development of gender-related math attitudes. Sex Roles, 66, 156-166. doi: 10.1007/s11199-011-99962

Hofstede, G. (2003). Culture's consequences. Thousand Oaks, CA: Sage.

Holopainen, L., Kairaluoma, L., Nevala, J., Ahonen, T., \& Aro, M. (2004). Lukivaikeuksien seulontatesti nuorille ja aikuisille. [Dyslexia screening test for youth and adults]. Jyväskylä: Jyväskylän yliopistopaino.

Jacobs, J. E. (1991). Influence of gender stereotypes on parent and child mathematics attitudes, Journal of Educational Psychology, 83, 518-527. doi: 10.1037/0022-0663.83.4.518

Jacobs, J. E., \& Eccles, J. S. (2000). Parents, task values, and real-life achievement-related choices. In C. Sansone \& J. M. Harackiewicz (Eds.), Intrinsic and extrinsic motivation: The search for optimal motivation and performance (pp. 405-439). San Diego, CA: Academic Press, Inc.

Jacobs, J. E., Lanza, S., Osgood, D. W., Eccles, J. S., \& Wigfield, A. (2002). Changes in children's selfcompetence and values: Gender and domain differences across grades one through twelve. Child Development, 73, 509-527. doi: 10.1111/1467-8624.00421

Lau, S., \& Pun, K-T. (1999). Parental evaluations and their agreement: Relationship with children's selfconcepts. Social Behavior and Personality: an international journal, 27, 639-650. doi: 10.2224/sbp.1999.27.6.639

Maccoby, E. E. (1998). The two sexes: Growing up apart, coming together. Cambridge, MA: Belknap Press. 
Marsh, H. W. (1990). A multidimensional, hierarchical self-concept: Theoretical and empirical justification. Educational Psychology Review, 2, 77-172. doi: 10.1007/BF01322177

Marsh, H. W., Byrne, B. M., \& Shavelson, R. (1988). A multifaceted academic self-concept: Its hierarchical structure and its relation to academic achievement. Journal of Educational Psychology, 80, 366-380. doi: $10.1037 / 0022-0663.80 .3 .366$

Marsh, H. W., Trautwein, U., Lüdtke, O., Köller, O. \& Baumert, J. (2005). Academic self-concept, interest, grades, and standardized test scores: Reciprocal effects models of causal ordering. Child Development, 76, 397-416. doi: 10.1111/j.1467-8624.2005.00853.x

Marsh, H. W., \& Yeung, A. S. (2001). An extension of the internal/external frame of reference model: A response to Bong (1998). Multivariate Behavioral Research, 36, 389-420. doi: 10.1207/S15327906389420

McGrath, E. P., \& Repetti, R. L. (2000). Mothers' and fathers' attitudes toward their children's academic performance and children's perceptions of their academic competence. Journal of Youth and Adolescence, 29, 713-723. doi: 10.1023/A:1026460007421

Nagy, G., Watt, H. M. G., Eccles, J., Trautwein, U., Lüdtke, O., \& Baumert, J. (2010). The development of students' mathematics self-concept in relation to gender: Different countries, different trajectories? Journal of Research on Adolescence, 20, 482-506. doi: 10.1111/j.1532-7795.2010.00644.x

Pesu, L., Viljaranta, J., \& Aunola, K. (2016). The role of parents' and teachers' beliefs in children's selfconcept development. Journal of Applied Developmental Psychology, 44, 63-71. doi: 10.1016/j.appdev.2016.03.001

Phillips, D. A. (1987). Socialization of perceived academic competence among highly competent children. Child Development, 58, 1308-1320. doi: 10.2307/1130623

Pintrich, P. R. \& Schunk, D. H. (2008). Motivation in education. Theory, research and applications (3rd ed.). New Jersey: Pearson Education.

Preckel, F., Niepel, C., Schneider, M., \& Brunner, M. (2013). Self-concept in adolescence: A longitudinal study on reciprocal effects of self-perceptions in academic and social domains. Journal of Adolescence, 36, 1165-1175. doi: 10.1016/j.adolescence.2013.09.001

Räsänen, P., \& Leino, L. (2005). KTLT. Laskutaidon testi. Opas yksilö-tai ryhmämuotoista arviointia varten.

Seymour, P. H., Aro, M., \& Erskine, J. M. (2003). Foundation literacy acquisition in European orthographies. British Journal of Psychology, 94, 143-174. doi: 10.1348/000712603321661859

Shavelson. R. J., Hubner, J. J., \& Stanton, G. C. (1976). Self-concept: Validation of construct interpretations. Review of Educational Research, 46, 407-441. doi: 10.2307/1170010

Simpkins, S. D., Fredricks, J. A., \& Eccles, J. S. (2012). Charting the Eccles' expectancy-value model from mothers' beliefs in childhood to youths' activities in adolescence. Developmental Psychology, 48, 1019-1032. doi: $10.1037 / \mathrm{a} 0027468$

Statistics Finland (2010). Differences between municipalities in educational level of population were still considerable in 2009. Helsinki: Statistics Finland. Retrieved March 20, 2016, from http:// www.stat.fi/til/vkour/2009/vkour_2009_2010-12-03_tie_001_en.html

Valentine, J. C., DuBois, D. L., \& Cooper, H. (2004). The relation between self-beliefs and academic achievement: A meta-analytic review. Educational Psychologist, 39, 111-133. doi: $10.1207 / \mathrm{s} 15326985 \mathrm{ep} 3902 \_3$

Välijärvi, J., Kupari, P., Linnakylä, P., Reinikainen, P., Sulkunen, S., Törnroos, J., \& Arffman, I. (2007). The Finnish success in Pisa-and some reasons behind it: Pisa 2003. 2. Jyväskylän yliopisto, Koulutuksen tutkimuslaitos.

Watt, H. M. G. (2004). Development of adolescents' self-perceptions, values, and task-perceptions according to gender and domain in 7th- through 11th-grade Australian students. Child Development, 75, 15561574. doi: $10.1111 / \mathrm{j} .1467-8624.2004 .00757 . x$

Wigfield, A., \& Eccles, J. S. (2000). Expectancy-value theory of achievement motivation. Contemporary Educational Psychology, 25, 68-81. doi: 10.1006/ceps.1999.1015

Wigfield, A., Eccles, J. S., MacIver, D., Reuman, D. A., \& Midgley, C. (1991). Transitions during early adolescence: Changes in children's domain-specific self-perceptions and general self-esteem across the 
transition to junior high school. Developmental Psychology, 27, 552-565. doi: 10.1037/00121649.27.4.552

Wigfield, A., Eccles, J. S., Schiefele, U, Roeser, R. W., \& Davis-Kean, P. (2006). Development of achievement motivation. In N. Eisenberg, W. Damon \& R. M. Lerner (Eds.), Handbook of child psychology: Vol. 3, Social, emotional, and personality development (6th Ed.) (pp. 933-1002). Hoboken, NJ, US: John Wiley \& Sons Inc.

Wigfield, A., Eccles, J. S., Yoon, K. S., Harold, R. D., Arbreton, A. J. A., Freeman-Doan, C., \& Blumenfeld, P. C. (1997). Change in children's competence beliefs and subjective task values across the elementary school years: A 3-year study. Journal of Educational Psychology, 89, 451-469. doi: 10.1037/0022-0663.89.3.451

Wigfield, A., Tonks, S., \& Eccles, J. S. (2004). Expectancy value theory in cross-cultural perspective. In D. M. McInerney \& S. van Etten (eds.), Big theories revisited (pp. 165-198). Charlotte, NC:IAP. 